\title{
Association between subthreshold depression and self-care behaviours in people with type 2 diabetes: a systematic review of observational studies
}

\author{
Monika Shrestha ( $\triangle$ monikasthaa@gmail.com ) \\ Nepal Diabetic Society https://orcid.org/0000-0003-2517-4608 \\ Ashley $\mathbf{N g}$ \\ La Trobe University School of Allied Health \\ Amal Al-Ghareeb \\ Independent Researcher \\ Fatimah Alenazi \\ La Trobe University School of Nursing and Midwifery \\ Richard Gray \\ La Trobe University School of Nursing and Midwifery
}

\section{Research}

Keywords: Subthreshold depression, depression, self-care behaviours, self- management, type 2 diabetes, systematic review

Posted Date: December 20th, 2019

DOI: https://doi.org/10.21203/rs.2.19278/v1

License: (c) (i) This work is licensed under a Creative Commons Attribution 4.0 International License. Read Full License

Version of Record: A version of this preprint was published at Systematic Reviews on July 12th, 2019. See the published version at https://doi.org/10.1186/s13643-019-1084-7. 


\section{Abstract}

Background

Self-care behaviours in people living with type 2 diabetes are important to achieving optimal glycemic control. Major depression in type 2 diabetes is associated with decreased adherence to self-care behaviours. The association between subthreshold depression and self-care behaviours, however, has not previously been systematically reviewed.

Methods

Five electronic databases were searched to identify observational studies in adults with type 2 diabetes investigating the association between subthreshold depression and self-care behaviours. Two reviewers independently completed title and abstract and full-text screening, appraised study quality, and extracted the data. Included articles were critically appraised using the Joanna Briggs Institute (JBI) Critical Appraisal Checklist.

Results

A total of 6,408 articles were identified through the database searching. After the abstract and full-text review, two articles met the inclusion criteria. Due to a limited number of studies, a meta-analysis could not be done. The two studies showed inconsistent findings on the association between subthreshold depression and self-care behaviours. Important risks of bias were identified in both the included studies.

\section{Conclusions}

There is no clear evidence that subthreshold depression is associated with self-care behaviours in adults with type 2 diabetes. Our review established a gap in knowledge and suggests that further high-quality studies are needed to examine the association between subthreshold depression and self-care behaviours in people with type 2 diabetes.

Systematic review registration: PROSPERO CRD42018116373

\section{Background}

The global prevalence of diabetes is rapidly escalating as a result of several factors including urbanization, economic development, population ageing, unhealthy eating habits, and sedentary lifestyles (1). Over the past two decades, the number of people living with type 2 diabetes (T2D) worldwide has more than doubled (2). International Diabetes Federation estimated that 1 in 11 adults aged 20-79 years (463 million) were living with T2D in 2019, and by 2045 this number is projected to rise to 700 million (3).

Type 2 diabetes, like other chronic diseases, is associated with an increased risk of comorbid health problems, including depression. Authors of a metaanalysis based on 248 studies and 83,020,812 participants reported that $28 \%$ of adults with T2D had a co-occurring depressive disorder (4). People with T2D are twice as likely to develop depression, compared to the general population (5-7). Comorbid depression in people with T2D is generally associated with poorer health outcomes including sub-optimal glycemic control (8-10), higher rates of diabetes related complications $(11,12)$, poorer quality of life $(13,14)$ and increased risk of mortality $(15,16)$. There is also evidence of an association between T2D, depression, and higher health care costs $(17)$.

The association between subthreshold depression and T2D has not been extensively studied. Subthreshold depression occurs when an individual experiences depressive symptoms that do not meet the diagnostic threshold for a major depressive disorder (MDD) with respect to frequency, severity and/or duration of symptoms $(18,19)$. Common in adults, a systematic review of 19 studies estimated the prevalence of subthreshold depression between $3 \%$ and $10 \%$ in clinical and between $1 \%$ and $17 \%$ in community settings (19).

In some studies of people with T2D, the prevalence of subthreshold depression has been reported to be more common than a major depressive disorder (2022). Like major depression, subthreshold depression is also associated with a higher rate of diabetes-related complications (11, 13), disability (11) and mortality $(11,23,24)$. There is some indicative evidence that subthreshold depression may be associated with an increase in HbA1c level $(25)$. Further, subthreshold depression is associated with an increased risk of developing major depressive disorder (MDD). For example, a meta-analysis of 16 longitudinal cohort studies involving 67,318 participants identified that people with subthreshold depression were twice as likely than non-depressed people to develop MDD (26).

Effective management of diabetes requires adherence to self-care behaviours. In diabetes, self-care behaviours include monitoring diet, engaging in physical activity, routinely checking blood sugar levels, medication adherence, and active foot care (27). Good adherence with self-care behaviours has shown to be associated with improved glycemic control (28-31), fewer diabetes-related complications (32), a decrease in the use of health services (33) and an improvement in quality of life (34).

People with T2D and MDD often demonstrate poor diabetes self-care behaviours. A meta-analysis by Gonzalez, Peyrot (35). A systematic review of 27 studies and 7,266 people with T2D observed that depression was associated with low adherence to diet and physical activity (36). There may be an association between subthreshold depression and self-care behaviours in people with T2D. To the best of our knowledge, there has been no systematic review on this topic. This systematic review aims to examine the association between subthreshold depression and self-care behaviours in adults with T2D.

\section{Methods}


This systematic review is reported following the Preferred Reporting Items for Systematic Reviews and Meta-Analyses (PRISMA) guidelines (37) (Additional File 1). The review was prospectively registered at the International Prospective Register of Systematic Reviews (PROSPERO) on 28th November 2018 (https://www.crd.york.ac.uk/PROSPERO/, registration number: CRD42018116373). A detailed summary of the review methods is set out in protocol, which has been published elsewhere (38).

\section{Eligibility criteria}

The review included studies if they; i) were conducted in adults aged 18 years or over and diagnosed with type 2 diabetes, ii) were any observational studies (cross-sectional, case-control or cohort), iii) examined the association between subthreshold depression and any diabetes self-care behaviours and iv) were published in English. Studies were excluded if they were qualitative studies, review articles, and non-peer reviewed (grey) literature.

The self-care behaviours that were considered in the study were healthy eating, being physically active, monitoring of blood glucose, taking medication, not smoking, and foot care (27). Currently, there is no agreed definition of subthreshold depression. Different terms - e.g. minor, subthreshold - are used to describe people with subthreshold depression (19). For the purposes of our review we defined subthreshold depression as minor, subthreshold, subclinical, subsyndromal depression or a mood disorder that does not meet the diagnostic criteria for major depressive disorder (39).

\section{Data source and search strategy}

The search strategy was developed in consultation with a medical librarian experienced in systematic review database searching. We conducted a systematic search of the literature in the following databases: MEDLINE, EMBASE, PsycINFO, Emcare, and CINAHL. Databases were searched using a combination of medical subject headings (MeSH) and keywords relating to "type 2 diabetes", "depression" and "self-care." Boolean operators ("AND," and "OR"), proximity operators ("ADJ," and "N") and truncation were incorporated into the search strategy as required to cater for the different use of terms. Search results were limited to English. Additional file 2 shows the Medline (ovid) search strategy used for this systematic review.

\section{Study selection}

All the references identified were imported into Endnote X9 (40), a reference manager software program. Following the removal of duplicates in Endnote, citations were imported into Covidence systematic review software (41). All studies were then assessed for eligibility in Covidence on a two-step process, 1. title and abstract screening, and 2. screening of full texts. Two authors MS and FA, applied the predetermined eligibility criteria to all the articles by screening titles and abstracts independently. All disagreements concerning inclusion or exclusion of papers were judged by a third author (AG). Full-text reading of the articles was again done independently by two authors (MS and FA). The final decision on the inclusion of the full- text articles was made after a discussion with the review team members.

\section{Data extraction}

Two authors (MS and RG) independently extracted data from each of the included studies in the data extraction tool. A third author compared the authors' data and resolved inconsistencies by referring to the full-text article and thorough discussion. The following data were extracted: citation, country of study, aim of the study, population characteristics (age, gender), study design (cross-sectional, case-control or cohort) and setting (community or hospital), sample size, sample size calculation, sampling technique, data source (survey or secondary data), definition of subthreshold depression, measure used to examine subthreshold depression and self-care behaviours, analysis, confounder variables adjusted and key observation of the study. There was no need to contact the authors of any studies for the study information.

\section{Quality Appraisal}

All the included studies were assessed for methodological rigour using the Joanna Briggs Institute (JBI) Critical Appraisal Checklist tool (42). The JBI has separate checklists for cross-sectional (8 criteria), case-control (10 criteria), and cohort studies ( 11 criteria). Each component of the checklist was rated as yes, no, unclear, or not applicable. Two authors (MS and RG) independently evaluated the quality of each study, and disagreement between them were resolved by discussion within the review team.

\section{Data analysis}

Due to a smaller number of studies and variability in the outcome measures, results could not be combined by meta-analysis. Instead, a narrative synthesis of the study was conducted. Tables and narrative summaries are used to present the study and participant characteristics and findings of the studies.

\section{Results \\ Search results}


Details of the study selection process and search results is shown in Fig. 1. We identified a total of 6,408 articles based on the systematic literature search in five databases: MEDLINE $(n=1,147)$, EMBASE $(n=2955)$, PsycINFO $(n=447)$, Emcare $(n=1090)$ and CINAHL $(n=769)$. After removal of duplicates, the title and abstracts of 3,674 articles were screened. Forty-seven studies were selected for a full-text review. Articles were excluded, generally, because study authors did not report on the association between subthreshold depression and self-care behaviours. Two studies that met the eligibility criteria were included in the review.

\section{Study characteristics}

Both the included studies were hospital-based. Shin et al. reported a cross-sectional survey of 103 outpatients in the United States (43), and a longitudinal study of 866 primary care attenders in Germany was reported by Dirmaier et al. (44). Table 1 shows selected characteristics of the two included studies.

Table 1

Characteristics of included studies

\begin{tabular}{|c|c|c|c|c|c|c|c|c|c|c|}
\hline Citation & $\begin{array}{l}\text { Country } \\
\text { of study }\end{array}$ & Aim of the study & $\begin{array}{l}\text { Study } \\
\text { population } \\
\text { characteristics }\end{array}$ & $\begin{array}{l}\text { Study } \\
\text { design }\end{array}$ & $\begin{array}{l}\text { Study } \\
\text { setting }\end{array}$ & $\begin{array}{l}\text { Sample } \\
\text { size/ } \\
\text { Sample } \\
\text { size } \\
\text { calculation }\end{array}$ & $\begin{array}{l}\text { Sampling } \\
\text { technique }\end{array}$ & $\begin{array}{l}\text { Data } \\
\text { source }\end{array}$ & $\begin{array}{l}\text { Definition of } \\
\text { subthreshold } \\
\text { depression }\end{array}$ & $\begin{array}{l}\text { Measure } \\
\text { used }\end{array}$ \\
\hline $\begin{array}{l}\text { Dirmaier } \\
\text { et al. } \\
(2010)\end{array}$ & Germany & $\begin{array}{l}\text {-To investigate } \\
\text { the effect of } \\
\text { depression on } \\
\text { adherence to } \\
\text { medical } \\
\text { recommendation } \\
\text { (concerning } \\
\text { medication } \\
\text { adherence and } \\
\text { health } \\
\text { behaviour) and } \\
\text { - To investigate } \\
\text { the effect of } \\
\text { depression and } \\
\text { adherence to } \\
\text { medical } \\
\text { recommendation } \\
\text { (medication } \\
\text { adherence and } \\
\text { health } \\
\text { behaviour) on } \\
\text { HbA1c }\end{array}$ & $\begin{array}{l}\text { Type } 2 \\
\text { diabetes } \\
\text { patients aged } \\
18 \text { years or } \\
\text { older } \\
\text { Mean age: } \\
65.7 \text { years } \\
\text { Female: } 48.8 \%\end{array}$ & $\begin{array}{l}\text { Longitudinal } \\
\text { study }\end{array}$ & $\begin{array}{l}\text { Hospital } \\
\text { based } \\
\text { in } \\
\text { Primary } \\
\text { care }\end{array}$ & $\begin{array}{l}866 / \text { not } \\
\text { specified }\end{array}$ & $\begin{array}{l}\text { Random } \\
\text { sampling }\end{array}$ & $\begin{array}{l}\text { DETECT } \\
\text { study of } \\
55,518 \\
\text { patients }\end{array}$ & $\begin{array}{l}\text { DSQ score } \\
\text { between 5-7 } \\
\text { indicated } \\
\text { subthreshold } \\
\text { depression }\end{array}$ & $\begin{array}{l}\text {-Depress } \\
\text { screenin } \\
\text { question } \\
\text { (DSQ) } \\
\text {-Medicat } \\
\text { non- } \\
\text { adherenı } \\
\text { one ques } \\
\text {-Non- } \\
\text { adherenı } \\
\text { with hea } \\
\text { behavior } \\
\text { item } \\
\text { question }\end{array}$ \\
\hline $\begin{array}{l}\text { Shin et } \\
\text { al. } \\
(2017)\end{array}$ & USA & $\begin{array}{l}\text { To examine } \\
\text { whether } \\
\text { problem-solving } \\
\text { and diabetes } \\
\text { self-care } \\
\text { behaviors } \\
\text { differed by } \\
\text { depressive } \\
\text { disorder } \\
\text { diagnosis }\end{array}$ & $\begin{array}{l}\text { Type } 2 \\
\text { diabetes } \\
\text { patients aged } \\
18 \text { years or } \\
\text { older } \\
\text { Mean age: } \\
58 \text { years } \\
\text { Female: } 59 \%\end{array}$ & $\begin{array}{l}\text { Cross- } \\
\text { sectional } \\
\text { study }\end{array}$ & $\begin{array}{l}\text { Hospital } \\
\text { based }\end{array}$ & $\begin{array}{l}\text { 103/ not } \\
\text { specified }\end{array}$ & $\begin{array}{l}\text { All } \\
\text { patients } \\
\text { with type } \\
2 \\
\text { diabetes } \\
\text { seen in } \\
\text { the clinic } \\
\text { between } \\
1 \text { st Feb } \\
2011 \text { and } \\
30 \text { th } \\
\text { June } \\
2013 \text {. }\end{array}$ & $\begin{array}{l}\text { Primary } \\
\text { (data } \\
\text { from } \\
\text { patients } \\
\text { attending } \\
\text { Diabetes } \\
\text { Center } \\
\text { Clinics at } \\
\text { John } \\
\text { Hopkins) }\end{array}$ & $\begin{array}{l}\text { DSM-IV } \\
\text { criteria for } \\
\text { Minor } \\
\text { Depression }\end{array}$ & $\begin{array}{l}\text {-PHQ-2 } \\
\text { followed } \\
\text { SCID-I/N } \\
\text {-Summa } \\
\text { Diabetes } \\
\text { care Acti } \\
\text { (SDSCA) }\end{array}$ \\
\hline
\end{tabular}

SCID-I/NP: Structured Clinical Interview for the DSM-IV Axis I Disorders, non-patient edition

\section{How was subthreshold depression determined?}

The exposure, subthreshold depression, was determined using different procedures in the included studies. Dirmaier et al. classified participants as having subthreshold depression or depression if they had a Depression Screening Questionnaire (DSQ) score of between 5 and 7 or 8 or higher, respectively (44). Shin et al. used a two-step process to make a depression diagnosis (43). Initially, a screening questionnaire, the two-item version of the Patient Health Questionnaire (PHQ-2) (45), was completed and scored. Participants with a score of three or higher were assessed by a clinician using the Structured Clinical Interview for the Diagnostic and Statistical Manual of Mental Disorders- IV (DSM-IV) Axis I Disorders, non-patient edition (46). Also, participants taking any antidepressant medication (for any reason) and those who already had an MDD diagnosis were interviewed by a researcher. Participants were determined to have minor or major depression if they met DSM-IV diagnostic criteria (47).

\section{How were self-care behaviours determined?}

In the Dirmaier et al. study, six items in the questionnaire were used to determine self-care behaviours (44): A single item was used to determined medication non-adherence and five items to determine non-adherence to other health behaviours (diet (2 items), smoking, alcohol and physical activity). Shin et al. (43) 
used the Summary of Diabetes self-care activities (SDSCA) (48) to determine participants level of self-care behaviours during the past seven days. Self-care behaviours were assessed in five domains, which included diet, exercise, foot care, blood sugar testing, and medication taking. The overall self-care behaviour was calculated by adding up the scores of all the domains.

\section{Participant characteristics}

Participant characteristics are shown in Table 1. Included studies involved 968 adults (aged 18 years and above) participants. In both the studies, males and females were equally represented $(43,44)$. Subjects in the Dirmaier et al. study $(44)$ were older than those in Shin et al. study (43). Mean diabetes duration was around ten years in both studies $(43,44)$.

\section{Quality appraisal}

Quality appraisal of included studies is shown in Table 2. Since none of the included studies were of a case-control study design, the JBI critical appraisal checklist tool for cross-sectional and cohort studies were used. None of the studies was excluded based on their quality appraisal.

Table 2

Quality appraisal of included studies

\begin{tabular}{|c|c|c|c|c|c|c|}
\hline Study & & Cross-sectional study & Yes & No & Unclear & $\begin{array}{l}\text { Not } \\
\text { applicable }\end{array}$ \\
\hline \multirow{8}{*}{$\begin{array}{l}\text { Shin et al. } \\
\text { (2017) }\end{array}$} & 1. & Were the criteria for inclusion in the sample clearly defined? & & & $\mathrm{x}$ & \\
\hline & 2. & Were the study subjects and the setting described in detail? & & & $\mathrm{x}$ & \\
\hline & 3. & Was the exposure measured in a valid and reliable way? & $\mathrm{x}$ & & & \\
\hline & 4. & Were objective, standard criteria used for measurement of the condition? & $x$ & & & \\
\hline & 5. & Were confounding factors identified? & & & $\mathrm{X}$ & \\
\hline & 6. & Were strategies to deal with confounding factors stated? & $\mathrm{x}$ & & & \\
\hline & 7. & Were the outcomes measured in a valid and reliable way? & $\mathrm{x}$ & & & \\
\hline & 8. & Was appropriate statistical analysis used? & $\mathrm{X}$ & & & \\
\hline Study & & Cohort study & & & & \\
\hline \multirow{10}{*}{$\begin{array}{l}\text { Dirmair et al. } \\
(2010)\end{array}$} & 1. & Were the two groups similar and recruited from the same population? & $\mathrm{x}$ & & & \\
\hline & 2. & $\begin{array}{l}\text { Were the exposures measured similarly to assign people } \\
\text { to both exposed and unexposed groups? }\end{array}$ & $\mathrm{x}$ & & & \\
\hline & 3. & Was the exposure measured in a valid and reliable way? & $\mathrm{X}$ & & & \\
\hline & 4. & Were confounding factors identified? & $\mathrm{x}$ & & & \\
\hline & 5. & Were strategies to deal with confounding factors stated? & $\mathrm{X}$ & & & \\
\hline & 6. & $\begin{array}{l}\text { Were the groups/participants free of the outcome at the start of the study (or at the } \\
\text { moment of exposure)? }\end{array}$ & & & & $\mathrm{X}$ \\
\hline & 7. & Were the outcomes measured in a valid and reliable way? & & $\mathrm{X}$ & & \\
\hline & 8. & Was the follow up time reported and sufficient to be long enough for outcomes to occur? & $\mathrm{x}$ & & & \\
\hline & 9. & $\begin{array}{l}\text { Was follow up complete, and if not, were the reasons to loss to follow up described and } \\
\text { explored? }\end{array}$ & & & $\mathrm{x}$ & \\
\hline & 10. & Were strategies to address incomplete follow up utilized? & & & $\mathrm{x}$ & \\
\hline
\end{tabular}

Several potentially important sources of bias were identified in the Shin et al. study (43). Five items were rated low, and three unclear risk of bias. The most important source of potential bias was related to confounding, as authors adjusted for three confounders (age, sex, and diabetes duration) in their analysis. Other potential confounders may have impacted the strength of the observed association. Eligibility criteria were not clearly stated, and the setting where the research was conducted was not sufficiently detailed. Although the authors articulated clear hypotheses, the authors did not report a sample size calculation; consequently, it cannot be determined if the sample size was appropriate to test the expressed hypotheses.

In the study by Dirmaier et al., three of eleven items were rated as potential sources of bias (44). Of particular concern, key variables were determined using measures that were developed specifically for the study - e.g., medication non-adherence - despite validated measures being available. The flow of participants through the study is not clear and that authors do not state strategies to address the incomplete follow-up.

\section{Association between subthreshold depression and self-care behaviours}


Dirmaier et al. reported that subthreshold depression was associated with non-adherence to health behaviour over a period of twelve months follow-up (44). The association was retained $(\beta=1.01 ; \mathrm{Cl}: 0.62-1.40 ; p<0.001)$ after adjusting for gender, age, marital and employment status, education, physical activity, $\mathrm{BMl}$, smoking, drinking, duration of diabetes and type of diabetes treatment. No significant association between subthreshold depression and medication nonadherence was observed.

Shin et al. reported that individuals with T2D and subthreshold depression scored lower in their self-care behaviour as compared to the group without depression (43). However, there was no significant association between subthreshold depression and the overall self-care behaviour or individual self-care domains (diet, exercise, blood sugar, foot care, and medication).

\section{Discussion}

This is the first review to systematically appraise and synthesize studies examining the association between subthreshold depression and diabetes self-care behaviours in adults with T2D. Our review included two studies involving 968 participants. Important potential sources of bias were identified in both included studies. One study showed a significant and the other a non-significant association between subthreshold depression and self-care behaviours. Due to a lack of sufficient evidence, the association between subthreshold depression and self-care behaviours in people with T2D is inconclusive.

In people with T2D and MDD, there is clear evidence of an association with adherence to self-care behaviours. It is perhaps surprising that so few studies have tested this association in patients with T2D and subthreshold depression. Subthreshold depression is prevalent in T2D, affecting around 12\% of patients (22). Examining the association between subthreshold depression and self-care is perhaps an important area for further enquiry. Policymakers and researchers should prioritize further observational and experimental research in this area. If subthreshold depression is associated with decreased adherence to self-care behaviours, treatment, and management of subthreshold depression should become an important aspect of recommended guidelines for diabetes care. Effective management of subthreshold depression in people with T2D could prevent them from progressing into major depression.

The present review has several limitations that need consideration. First, the review considered six domains of diabetes self-care behaviours that are often recommended for people with T2D: diet, physical activity, blood glucose monitoring, medication, foot care, and smoking. Other self-care behaviours, such as attending a diabetes education program and those recommended by the American Association of diabetes educators such as problem-solving, were not considered in this review. A further limitation was the exclusion of the non-peer-reviewed literature. We may have missed some of the important data by not including grey literature in our review. However, as the validity of grey literature is difficult to be determined, this exclusion may be of less importance. Similarly, we limited our search to the English language. It may be possible that studies published in other languages might have provided additional data, especially in a case such as ours, where the evidence is limited.

\section{Conclusions}

This review identified two studies that examined the association between subthreshold depression and self-care behaviours in people with T2D. Due to a lack of sufficient evidence, we cannot conclude that subthreshold depression in T2D is associated with self-care behaviours. This limited evidence suggests that rigorously designed studies are needed to examine the relationship between these two which may subsequently help in planning the intervention to improve the self-management of people living with T2D.

\section{Abbreviations}

\begin{tabular}{|ll|}
\hline DSM-IV & Diagnostic and Statistical Manual of Mental Disorders- IV \\
\hline DSQ & Depression Screening Questionnaire \\
\hline JBI & The Joanna Briggs Institute \\
\hline MDD & Major depressive disorder \\
\hline PHQ & Patient Health Questionnaire \\
\hline PRISMA & Preferred Reporting Items for the Systematic Reviews and Meta-Analyses \\
\hline PROSPERO & International Prospective Register of Systematic Reviews \\
\hline SDSCA & Summary of diabetes self-care activities \\
\hline T2D & Type 2 diabetes \\
\hline
\end{tabular}

\section{Declarations}

\section{Ethics approval and consent to participate}

Not applicable

\section{Consent for publication}

Not applicable 
Availability of data and materials

All the data supporting the conclusion of this review is included within the article and its additional files.

\section{Competing interests}

The authors declare that they have no competing interests.

\section{Funding}

Not applicable

\section{Authors' contributions}

MS and RG jointly conceived and designed the study. MS developed the search strategies and it was verified by RG and AAG. MS and RG extracted the data and appraised the quality of included studies. AAG and FA resolved any disagreements. MS developed the first draft of the protocol, and RG, AAG, FA, and AN contributed to the revisions of the protocol. All the authors provided critical comments for revision and approved the final version of the manuscript.

\section{Acknowledgements}

This work was supported by a La Trobe University Postgraduate Research Scholarship (LTUPRS) and La Trobe University Full Fee Research Scholarship (LTUFFRS).

\section{References}

1. Zheng Y, Ley SH, Hu FB. Global aetiology and epidemiology of type 2 diabetes mellitus and its complications. Nat Rev Endocrinol. 2018;14(2):88-98.

2. Zimmet PZ, Magliano DJ, Herman WH, Shaw JE. Diabetes: a 21st century challenge. The lancet Diabetes \& endocrinology. 2014;2(1):56-64.

3. International Diabetes Federation. IDF Diabetes Atlas Ninth Edition2019. Available from: http://www.diabetesatlas.org/resources/2017-atlas.html.

4. Khaledi M, Haghighatdoost F, Feizi A, Aminorroaya A. The prevalence of comorbid depression in patients with type 2 diabetes: an updated systematic review and meta-analysis on huge number of observational studies. Acta Diabetol. 2019;56(6):631-50.

5. Ali S, Stone MA, Peters JL, Davies MJ, Khunti K. The prevalence of co-morbid depression in adults with Type 2 diabetes: a systematic review and metaanalysis. Diabet Med. 2006;23(11):1165-73.

6. Anderson RJ, Freedland KE, Clouse RE, Lustman PJ. The prevalence of comorbid depression in adults with diabetes: a meta-analysis. Diabetes Care. 2001;24(6):1069-78.

7. Roy T, Lloyd CE. Epidemiology of depression and diabetes: a systematic review. J Affect Disord. 2012;142 Suppl:S8-21.

8. Lustman PJ, Anderson RJ, Freedland KE, de Groot M, Carney RM, Clouse RE. Depression and poor glycemic control: a meta-analytic review of the literature. Diabetes Care. 2000;23(7):934-42.

9. Richardson LK, Egede LE, Mueller M, Echols CL, Gebregziabher M. Longitudinal effects of depression on glycemic control in veterans with Type 2 diabetes. Gen Hosp Psychiatry. 2008;30(6):509-14.

10. Zhang Y, Ting RZ, Yang W, Jia W, Li W, Ji L, et al. Depression in Chinese patients with type 2 diabetes: associations with hyperglycemia, hypoglycemia,

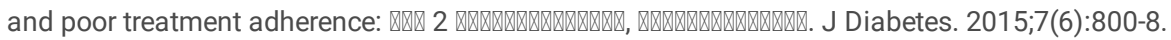

11. Black SA, Markides KS, Ray LA. Depression predicts increased incidence of adverse health outcomes in older Mexican Americans with type 2 diabetes. Diabetes Care. 2003;26(10):2822-8.

12. de Groot M, Anderson R, Freedland KE, Clouse RE, Lustman PJ. Association of depression and diabetes complications: a meta-analysis. Psychosom Med. 2001;63(4):619-30.

13. Egede LE, Ellis C. The effects of depression on metabolic control and quality of life in indigent patients with type 2 diabetes. Diabetes Technol Ther. 2010;12(4):257-62.

14. Goldney RD, Phillips PJ, Fisher LJ, Wilson DH. Diabetes, depression, and quality of life: a population study. Diabetes Care. 2004;27(5):1066-70.

15. Katon WJ, Rutter C, Simon G, Lin EH, Ludman E, Ciechanowski P, et al. The association of comorbid depression with mortality in patients with type 2 diabetes. Diabetes Care. 2005;28(11):2668-72.

16. Xuanping Z, Norris SL, Gregg EW, Cheng YJ, Beckles G, Kahn HS. Depressive symptoms and mortality among persons with and without diabetes. Am J Epidemiol. 2005;161(7):652-60.

17. Egede LE, Zheng D, Simpson K. Comorbid depression is associated with increased health care use and expenditures in individuals with diabetes. Diabetes Care. 2002;25(3):464-70.

18. National Collaborating Centre for Mental Health. Depression: the treatment and management of depression in adults (updated edition). Leicester, UK: British Psychological Society; 2010.

19. Rodríguez MR, Nuevo R, Chatterji S, Ayuso-Mateos JL. Definitions and factors associated with subthreshold depressive conditions: a systematic review. BMC Psychiatry. 2012;12(1):181.

20. Schmitz N, Gariepy G, Smith KJ, Clyde M, Malla A, Boyer R, et al. Recurrent subthreshold depression in type 2 diabetes: an important risk factor for poor health outcomes. Diabetes Care. 2014;37(4):970-8. 
21. Albertorio-Diaz JR, Eberhardt MS, Oquendo M, Mesa-Frias M, He Y, Jonas B, et al. Depressive states among adults with diabetes: Findings from the National Health and Nutrition Examination Survey, 2007-2012. Diabetes Res Clin Pract. 2017;127:80-8.

22. Wang D, Shi L, Li L, Guo X, Li Y, Xu Y, et al. Subthreshold depression among diabetes patients in Beijing: Cross-sectional associations among sociodemographic, clinical, and behavior factors. J Affect Disord. 2018;237:80-6.

23. Coleman SM, Katon W, Lin E, Von Korff M. Depression and death in diabetes; 10-year follow-up of all-cause and cause-specific mortality in a diabetic cohort. Psychosomatics. 2013;54(5):428-36.

24. Lin EH, Heckbert SR, Rutter CM, Katon WJ, Ciechanowski P, Ludman EJ, et al. Depression and increased mortality in diabetes: unexpected causes of death. The Annals of Family Medicine. 2009;7(5):414-21.

25. Heckbert SR, Rutter CM, Oliver M, Williams LH, Ciechanowski P, Lin EH, et al. Depression in relation to long-term control of glycemia, blood pressure, and lipids in patients with diabetes. J Gen Intern Med. 2010;25(6):524-9.

26. Lee Y, Stockings E, Harris M, Doi S, Page I, Davidson S, et al. The risk of developing major depression among individuals with subthreshold depression: a systematic review and meta-analysis of longitudinal cohort studies. Psychol Med. 2018:1-11.

27. American Association of Diabetes Educators. AADE guidelines for the practice of diabetes self-management education and training (DSME/T). The Diabetes Educator. 2009;35(3_suppl):85S-107S.

28. Houle J, Beaulieu MD, Chiasson JL, Lesperance F, Cote J, Strychar I, et al. Glycaemic control and self-management behaviours in Type 2 diabetes: results from a 1-year longitudinal cohort study. Diabet Med. 2015;32(9):1247-54.

29. Aikens J, Piette J. Longitudinal association between medication adherence and glycaemic control in type 2 diabetes. Diabet Med. 2013;30(3):338-44.

30. Poolsup N, Suksomboon N, Rattanasookchit S. Meta-analysis of the benefits of self-monitoring of blood glucose on glycemic control in type 2 diabetes patients: an update. Diabetes Technol Ther. 2009;11(12):775-84.

31. Tshiananga JK, Kocher S, Weber C, Erny-Albrecht K, Berndt K, Neeser K. The effect of nurse-led diabetes self-management education on glycosylated hemoglobin and cardiovascular risk factors: a meta-analysis. Diabetes Educ. 2012;38(1):108-23.

32. Ausili D, Rossi E, Rebora P, Luciani M, Tonoli L, Ballerini E, et al. Socio-demographic and clinical determinants of self-care in adults with type 2 diabetes: a multicentre observational study. Acta Diabetol. 2018;55(7):691-702.

33. Adepoju OE, Bolin JN, Phillips CD, Zhao HW, Ohsfeldt RL, McMaughan DK, et al. Effects of diabetes self-management programs on time-to-hospitalization among patients with type 2 diabetes: A survival analysis model. Patient Educ Couns. 2014;95(1):111-7.

34. Heinrich E, Schaper NC, de Vries NK. Self-management interventions for type 2 diabetes: a systematic review. European Diabetes Nursing. 2010;7(2):71-6.

35. Gonzalez JS, Peyrot M, McCarl LA, Collins EM, Serpa L, Mimiaga MJ, et al. Depression and diabetes treatment nonadherence: a meta-analysis. Diabetes Care. 2008;31(12):2398-403.

36. Sumlin LL, Garcia TJ, Brown SA, Winter MA, Garcia AA, Brown A, et al. Depression and adherence to lifestyle changes in type 2 diabetes: a systematic review. Diabetes Educ. 2014;40(6):731-44.

37. Moher D, Liberati A, Tetzlaff J, Altman DG, Group P. Preferred reporting items for systematic reviews and meta-analyses: the PRISMA statement. Int J Surg. 2010;8(5):336-41.

38. Shrestha M, Al-Ghareeb A, Alenazi F, Gray R. Association between subthreshold depression and self-care behaviour in people with type 2 diabetes: a protocol for systematic review of observational studies. Systematic reviews. 2019;8(1):167.

39. Sadek N, Bona J. Subsyndromal symptomatic depression: a new concept. Depress Anxiety. 2000;12(1):30-9.

40. Endnote.[Computer program]. Version X9. Philadelphia: Clarivate Analytics.

41. Veritas Health Innovation. Covidence systematic review software Melbourne, Australia [Available from: www.covidence.org.

42. Moola S, Munn Z, Tufanaru C, Aromataris E, Sears K, Sfetcu R, et al. Chapter 7: Systematic reviews of etiology and risk. Joanna Briggs Institute Reviewer's Manual The Joanna Briggs Institute. 2017.

43. Shin N, Hill-Briggs F, Langan S, Payne JL, Lyketsos C, Golden SH. The association of minor and major depression with health problem-solving and diabetes self-care activities in a clinic-based population of adults with type 2 diabetes mellitus. J Diabetes Complications. 2017;31(5):880-5.

44. Dirmaier J, Watzke B, Koch U, Schulz H, Lehnert H, Pieper L, et al. Diabetes in primary care: prospective associations between depression, nonadherence and glycemic control. Psychother Psychosom. 2010;79(3):172-8.

45. Kroenke K, Spitzer RL, Williams JB. The Patient Health Questionnaire-2: validity of a two-item depression screener. Med Care. 2003:1284-92.

46. First MB, Spitzer RL, Williams JB, Gibbon M. The Structured Clinical Interview for DSM-IV Axis I Disorders (SCID-I). 2000;2000:49-53.

47. First M, Gibbon M, Spitzer R, Williams J. User's Guide for the Structured Clinical Interview for DSM-IV-TR Axis I Disorders-Research Version-(SCID-I for DSM-IV-TR, November 2002 Revision). New York: Biometrics Research Department, New York State Psychiatric Institute. 2002.

48. Toobert DJ, Hampson SE, Glasgow RE. The summary of diabetes self-care activities measure: results from 7 studies and a revised scale. Diabetes Care. 2000;23(7):943-50.

\section{Figures}




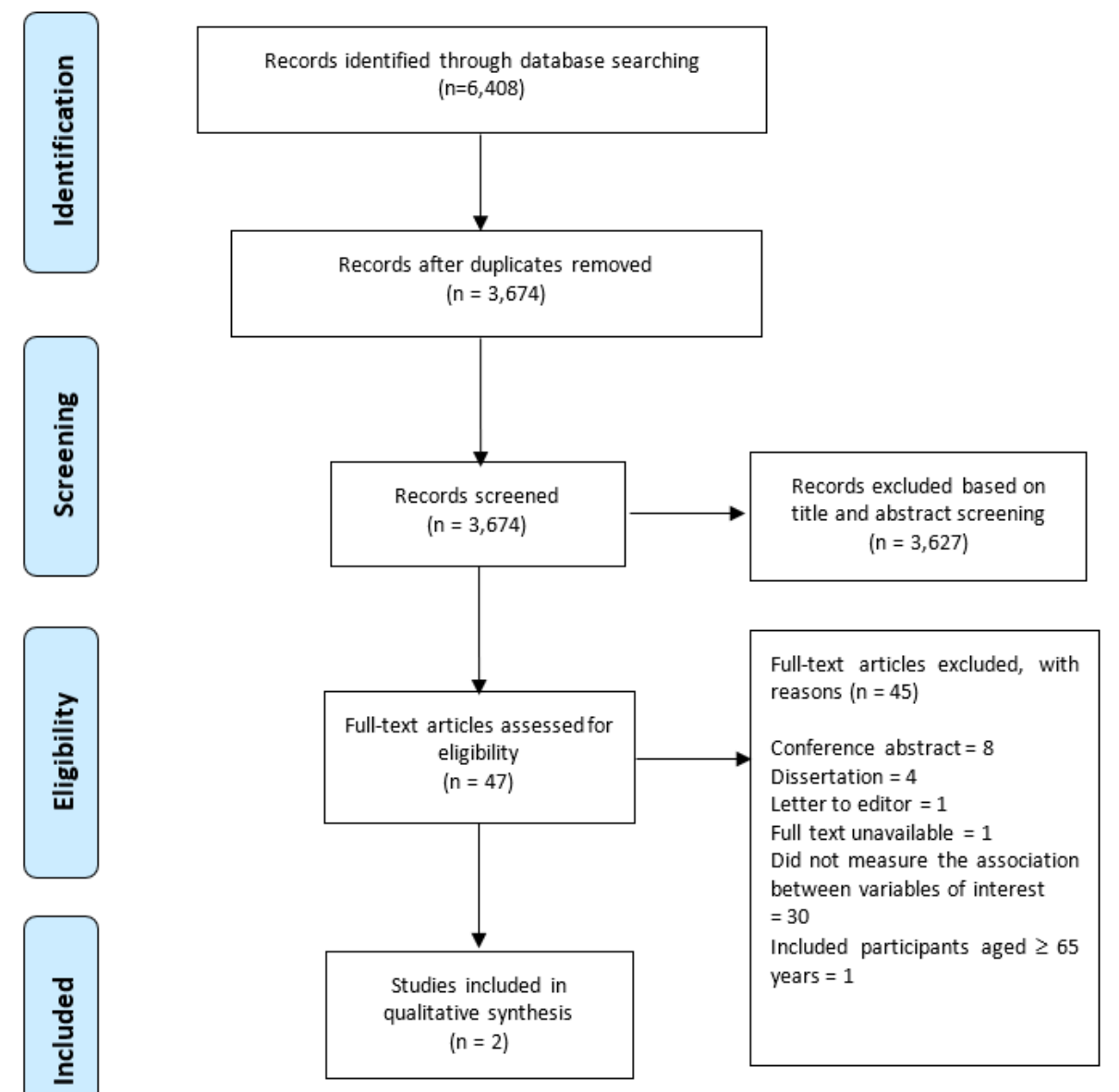

Figure 1

PRISMA flow chart showing the study selection process and search results

\section{Supplementary Files}

This is a list of supplementary files associated with this preprint. Click to download.

- AdditionalFile1.doc

- AdditionalFile2.docx 